Article

\title{
Dietary Phytoestrogen Intake is Inversely Associated with Hypertension in a Cohort of Adults Living in the Mediterranean Area
}

\author{
Justyna Godos $1,2, *$ (1) , Sonia Bergante ${ }^{3}$, Angela Satriano ${ }^{3}$, Francesca Romana Pluchinotta ${ }^{3}$ and \\ Marina Marranzano ${ }^{1}$ \\ 1 Department of Medical and Surgical Sciences and Advanced Technologies "G.F. Ingrassia", \\ University of Catania, 95125 Catania, Italy; marranz@unict.it \\ 2 Department of Biomedical and Biotechnological Sciences, University of Catania, 95123 Catania, Italy \\ 3 IRCCS Policlinico San Donato, 20097 San Donato Milanese (MI), Italy; sonia.bergante@unimi.it (S.B.); \\ angela.satriano@gmail.com (A.S.); francescaromana.pluchinotta@cardio.chboston.org (F.R.P.) \\ * Correspondence: justyna.godos@student.uj.edu.pl; Tel.: +39-095-378-2180
}

Received: 15 January 2018; Accepted: 6 February 2018; Published: 9 February 2018

\begin{abstract}
Background: Dietary polyphenols, including phytoestrogens are abundantly present in a balanced diet. Evidence for their role in preventing non-communicable diseases is emerging. Methods: We examined the association between estimated habitual intakes of dietary phytoestrogens and hypertension in a cohort study. The baseline data included 1936 men and women aged 18 years and older. Intakes of total phytoestrogens, isoflavones, and lignans were calculated from validated food frequency questionnaire. Data on the polyphenols content in foods were retrieved from the Phenol-Explorer database. Results: Individuals in the highest quartile of dietary phytoestrogens intake were less likely to be hypertensive (OR: 0.66, 95\% CI: 0.44-0.98); moreover, the association showed a significant decreasing trend. Isoflavones and lignans were not associated with lower odds of hypertension; however, some individual compounds, such as biochanin A and pinoresinol showed an independent inverse association with hypertension. Conclusions: Dietary phytoestrogens are associated with lower likelihood of hypertension in adults living in the Mediterranean area. Future studies are needed to confirm the present findings (i.e., prospective cohort studies) and to better understand the mechanisms underlying such associations.
\end{abstract}

Keywords: phytoestrogen; lignan; isoflavone; blood pressure; hypertension; CVD; meditteranean cohort

\section{Introduction}

Dietary polyphenols are the focus of major attention due to their potential beneficial effects on human health [1,2]. Among the others, phytoestrogens are a group of molecules with weak, yet clinically relevant, estrogen-like activity. Among the most studied groups of phytoestrogens, isoflavones and lignans have been demonstrated to be the most consumed in human diets [3]. Phytoestrogens bind to the estrogen receptors (ERs) and can act both as agonists and antagonists [4] Specifically, the dualistic mode of action of isoflavones depends on the fact that they can activate ER-alpha, promoting cell proliferation, and ER-beta, promoting apoptosis [4]. Lignans have been reported to weakly bind to ER-beta and stimulate estrogen-stimulated growth [5]. Generally, phytoestrogens have been studied for their ability to regulate cell proliferation/apoptosis and in relation to cancer risk/protection. However, recent evidence suggests that phytoestrogen-rich foods may play a role in modulating cardiovascular risk, providing the rationale to pay broader attention to these molecules for prevention of non-communicable diseases [6].

Phytoestrogens naturally occur in soy products, which are traditionally consumed in Asian countries; soy intake ranges approximately from 70 to $150 \mathrm{~g} / \mathrm{d}$ in Asian diets, corresponding to 
a daily intake of isoflavones of about 30 to $60 \mathrm{mg}$. However, phytoestrogens are also contained in certain legumes (i.e., beans and peas) and nuts as well as fruits, vegetables, grains and seeds [7]. Thus, their consumption, even though at lower amounts, has also been registered in US and European countries. Consumption of isoflavones has been estimated to be around $2.5 \mathrm{mg} / \mathrm{d}$ in both US and European countries, while average lignans intake in Europe is $1.5 \mathrm{mg} / \mathrm{d}$ [8,9]. However, dietary intake of phytoestrogens has been reported to be very low in populations living in the Mediterranean area: on average, taking into account countries such as Greece, Spain, and Italy, intake of both isoflavones and lignans ranges from $10 \mu \mathrm{g} / \mathrm{d}$ to up to approximately $1 \mathrm{mg} / \mathrm{d}$ [9,10]. However, another investigation conducted in Southern Italy showed higher average intake of both isoflavones $(4 \mathrm{mg} / \mathrm{d})$ and lignans (3 mg/d) [11]. Several studies have been conducted on Asian cohorts exploring the effects of soy/isoflavones and lignans on human health, but studies including individuals living in Mediterranean countries are scarce [12-14]. Even though soy products tend to be infrequently consumed in Mediterranean countries, there are other food sources of lignans that are common components of a traditional Mediterranean dietary pattern. Overall, the effect on hypertension of habitual low-dose consumption of phytoestrogens is unknown. Therefore, the aim of this study was to explore the association between dietary phytoestrogens intake and blood pressure (BP) in a cohort of southern Italian adults.

\section{Results}

Baseline characteristics of participants in the Mediterranean healthy eating, aging, and lifestyle (MEAL) study by quartiles of dietary phytoestrogens intake are described in Table 1.

Among individuals in the highest category of phytoestrogen intake, there was a higher percentage of females. Participants with higher total phytoestrogen intake had lower occupational levels. Regarding lifestyle behaviors, there was a higher prevalence of non-smokers, low physical active and regular alcohol drinkers among high phytoestrogen consumers compared to lower ones. With increasing intake of phytoestrogens, a higher intake of sodium and potassium was also observed. However, some differences occurred when analysis was stratified by sex: in the highest quartile of phytoestrogen intake men had lower educational level while women were younger (Supplementary Table S1).

A total number of 976 individuals were hypertensive or taking medication to reduce high BP. Participants with no hypertension had an appreciably higher mean intake of total phytoestrogens compared to hypertensive individuals $(8.33 \mathrm{mg} / \mathrm{d}$ vs. $5.19 \mathrm{mg} / \mathrm{d}$, respectively). To this difference mostly contributed mean amount of isoflavones intake between non-hypertensive and hypertensive individuals $(5.40 \mathrm{mg} / \mathrm{d}$ vs. $2.60 \mathrm{mg} / \mathrm{d}$, respectively; $p<0.001)$, while mean intake of lignans was rather similar, despite yet significantly different between the two groups $(2.92 \mathrm{mg} / \mathrm{d}$ vs. $2.59 \mathrm{mg} / \mathrm{d}$, respectively; $p=0.005)$. When the total phytoestrogens intake between non-hypertensive and hypertensive individuals was stratified by sex, the difference was larger for women $(9.72 \mathrm{mg} / \mathrm{d}$ vs. $5.68 \mathrm{mg} / \mathrm{d}$, respectively; $p<0.001)$ than for men $(5.78 \mathrm{mg} / \mathrm{d}$ vs. $4.65 \mathrm{mg} / \mathrm{d}$, respectively; $p=0.076)$, with similar pattern of difference for isoflavones and lignans (data not shown).

The relation between total phytoestrogens and BP levels showed a significant linear association with diastolic but not systolic blood pressure (SBP, Figure 1). 
Table 1. Baseline characteristics by quartiles of dietary phytoestrogens intake in the Mediterranean healthy eating, aging, and lifestyle (MEAL) study sample $(n=1936)$.

\begin{tabular}{|c|c|c|c|c|c|}
\hline & \multicolumn{4}{|c|}{ Total Phytoestrogens Intake } & \multirow{2}{*}{$p$} \\
\hline & Q1 $($ Median = 258.56) & Q2 (Median = 432.43) & Q3 (Median = 604.97) & Q4 $($ Median $=1054.63)$ & \\
\hline Age (years), mean (SD) & $47.9(18.7)$ & $49.4(17.2)$ & 49.5 (17.6) & $46.7(16.7)$ & 0.040 \\
\hline Sex, $n(\%)$ & & & & & 0.011 \\
\hline Male & $190(23.6)$ & $224(27.9)$ & $217(27.0)$ & $173(21.5)$ & \\
\hline Female & $272(24)$ & $271(23.9)$ & $276(24.4)$ & $313(27.7)$ & \\
\hline Educational level, $n$ (\%) & & & & & 0.434 \\
\hline Low & $161(23.1)$ & $168(24.1)$ & $188(27.0)$ & $180(25.8)$ & \\
\hline Medium & $168(23.3)$ & $195(27.1)$ & $188(26.1)$ & $169(23.5)$ & \\
\hline High & $133(25.6)$ & $132(25.4)$ & $117(22.5)$ & $137(26.4)$ & \\
\hline Occupational level, $n(\%)$ & & & & & 0.001 \\
\hline Unemployed & $109(23.6)$ & 85 (18.4) & $121(26.2)$ & $146(31.7)$ & \\
\hline Low & $51(19.2)$ & $57(21.4)$ & $88(33.1)$ & $70(26.3)$ & \\
\hline Medium & $109(24.8)$ & $119(27.0)$ & $113(25.7)$ & $99(22.5)$ & \\
\hline High & $131(26.7)$ & $125(25.5)$ & $131(27.3)$ & $104(25.3)$ & \\
\hline Smoking status, $n(\%)$ & & & & & 0.014 \\
\hline Non smoker & $270(22.6)$ & $296(24.8)$ & $301(25.2)$ & $328(27.4)$ & \\
\hline Ex-smoker & $121(26.0)$ & $121(26.0)$ & $111(23.9)$ & $112(24.1)$ & \\
\hline Current smoker & $71(25.7)$ & $78(28.3)$ & $81(29.3)$ & $46(16.7)$ & \\
\hline Physical activity, $n(\%)$ & & & & & $<0.001$ \\
\hline Low & $89(27.1)$ & $55(16.7)$ & $83(25.2)$ & $102(31.0)$ & \\
\hline Medium & $221(25.8)$ & $238(27.8)$ & $175(20.4)$ & $222(25.9)$ & \\
\hline High & $97(17.9)$ & $159(29.3)$ & $165(30.4)$ & $122(22.5)$ & \\
\hline Alcohol consumption, $n(\%)$ & & & & & $<0.001$ \\
\hline No & $97(25.9)$ & $95(25.3)$ & $84(22.4)$ & $99(26.4)$ & \\
\hline Moderate (<12 g/d) & $311(25.8)$ & $303(25.1)$ & $334(27.7)$ & $258(21.4)$ & \\
\hline $\operatorname{Regular}(\geq 12 \mathrm{~g} / \mathrm{d})$ & $54(15.2)$ & $97(27.2)$ & $75(21.1)$ & $130(36.5)$ & \\
\hline $\mathrm{Na}($ microg$/ \mathrm{d})$, mean $\pm \mathrm{SD}$ & $2724.6 \pm 1155.7$ & $2869.9 \pm 1045.8$ & $2870.8 \pm 1060.4$ & $2947.8 \pm 1147.3$ & 0.021 \\
\hline $\mathrm{K}($ microg $/ \mathrm{d})$, mean $\pm \mathrm{SD}$ & $2920.4 \pm 897.0$ & $3269.6 \pm 941.2$ & $3915.5 \pm 1068.3$ & $4589.9 \pm 1806.8$ & $<0.001$ \\
\hline Systolic blood pressure $(\mathrm{mmHg})$, mean $\pm \mathrm{SD}$ & $122.1 \pm 12.9$ & $121.3 \pm 12.4$ & $121.4 \pm 12.2$ & $121.5 \pm 13.8$ & 0.723 \\
\hline Diastolic blood pressure $(\mathrm{mmHg})$, mean $\pm \mathrm{SD}$ & $76.1 \pm 9.9$ & $75.7 \pm 9.9$ & $75.1 \pm 10.3$ & $73.4 \pm 11.2$ & $<0.001$ \\
\hline
\end{tabular}



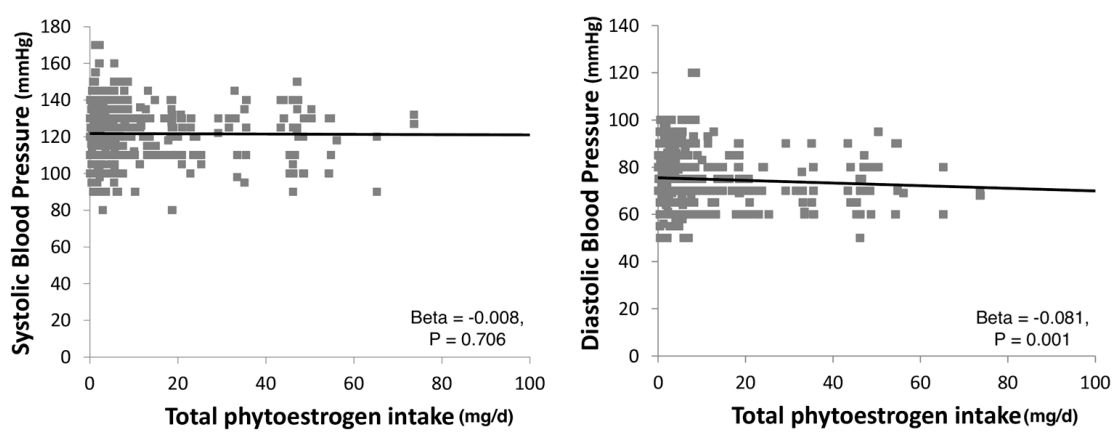

Figure 1. Association between dietary phytoestrogen intake and systolic and diastolic blood pressure (BP).

The association between quartiles of total and individual phytoestrogen intake and hypertension is reported in Table 2 .

Table 2. Association between quartiles of dietary phytoestrogens intake (total and main classes) and hypertension.

\begin{tabular}{|c|c|c|c|c|}
\hline \multirow[b]{2}{*}{ Polyphenols (mg/d) } & \multicolumn{4}{|c|}{ OR $(95 \% \mathrm{CI})$} \\
\hline & Q1 & Q2 & Q3 & Q4 \\
\hline Total phytoestrogens, median (range) & $0.89(0.20,1.23)$ & $1.77(1.24,2.33)$ & $3.61(2.33,5.41)$ & $10.21(5.42,101.72)$ \\
\hline No. of cases & 247 & 260 & 257 & 212 \\
\hline Model $^{\text {a }}$ & 1 & $0.85(0.63,1.14)$ & $0.79(0.58,1.07)$ & $0.68(0.49,0.96)$ \\
\hline Model ${ }^{b}$ & 1 & $0.87(0.61,1.26)$ & $0.69(0.47,1.00)$ & $0.66(0.44,0.98)$ \\
\hline Isoflavones, median (range) & $0.01(0.00,0.01)$ & $0.03(0.01,0.04)$ & $0.07(0.05,0.08)$ & $5.53(0.09,92.98)$ \\
\hline No. of cases & 240 & 267 & 265 & 204 \\
\hline Model $^{\text {a }}$ & 1 & $0.97(0.72,1.31)$ & $0.87(0.64,1.17)$ & $0.96(0.69,1.34)$ \\
\hline Model $^{\mathrm{b}}$ & 1 & $0.81(0.56,1.15)$ & $0.94(0.65,1.35)$ & $0.93(0.64,1.36)$ \\
\hline Daidzein, median (range) & $0.01(0.00,0.01)$ & $0.02(0.01,0.02)$ & $0.04(0.03,0.05)$ & $0.14(0.05,6.49)$ \\
\hline Model $^{\text {a }}$ & 1 & $1.14(0.84,1.55)$ & $1.03(0.76,1.40)$ & $0.94(0.68,1.29)$ \\
\hline Model ${ }^{b}$ & 1 & $0.95(0.66,1.36)$ & $1.05(0.73,1.52)$ & $1.03(0.70,1.51)$ \\
\hline Genistein, median (range) & $0.00(0.00,0.00)$ & $0.01(0.00,0.01)$ & $0.02(0.01,0.02)$ & $0.14(0.02,7.77)$ \\
\hline Model $^{\text {a }}$ & 1 & $1.23(0.91,1.65)$ & $1.04(0.76,1.42)$ & $0.99(0.72,1.36)$ \\
\hline Model ${ }^{b}$ & 1 & $1.05(0.73,1.49)$ & $1.08(0.73,1.58)$ & $1.07(0.73,1.57)$ \\
\hline Biochanin A, median (range) & $0.00(0.00,0.00)$ & $0.36(0.10,0.50)$ & $0.95(0.70,1.70)$ & $2.50(1.80,34.3)$ \\
\hline Model $^{a}$ & 1 & $0.99(0.72,1.35)$ & $1.24(0.91,1.69)$ & $0.63(0.46,0.87)$ \\
\hline Model ${ }^{b}$ & 1 & $0.99(0.65,1.48)$ & $0.99(0.66,1.50)$ & $0.63(0.41,0.96)$ \\
\hline Lignans, median (range) & $0.71(0.00,1.07)$ & $1.41(1.07,1.99)$ & $2.46(2.00,3.62)$ & $5.41(3.63,23.56)$ \\
\hline No. of cases & 225 & 232 & 275 & 244 \\
\hline Model $^{\text {a }}$ & 1 & $0.66(0.49,0.89)$ & $1.14(0.83,1.56)$ & $0.77(0.55,1.09)$ \\
\hline Model $^{\mathrm{b}}$ & 1 & $0.59(0.41,0.86)$ & $0.88(0.61,1.27)$ & $0.71(0.47,1.08)$ \\
\hline Lariciresinol, median (range) & $0.25(0.00,0.48)$ & $0.69(0.48,1.06)$ & $1.23(1.06,2.00)$ & $3.11(2.01,13.98)$ \\
\hline Model $^{a}$ & 1 & $0.65(0.48,0.88)$ & $1.03(0.76,1.40)$ & $0.79(0.56,1.10)$ \\
\hline Model ${ }^{b}$ & 1 & $0.60(0.41,0.86)$ & $0.84(0.58,1.21)$ & $0.69(0.46,1.03)$ \\
\hline Matairesinol, median (range) & $0.00(0.00,0.01)$ & $0.01(0.01,0.02)$ & $0.02(0.02,0.04)$ & $0.06(0.04,0.30)$ \\
\hline Model $^{\text {a }}$ & 1 & $1.00(0.74,1.35)$ & $1.47(1.07,2.01)$ & $1.03(0.73,1.44)$ \\
\hline Model ${ }^{b}$ & 1 & $0.95(0.65,1.37)$ & $1.08(0.74,1.58)$ & $0.91(0.60,1.38)$ \\
\hline Pinoresinol, median (range) & $0.31(0.00,0.41)$ & $0.52(0.41,0.70)$ & $0.87(0.70,1.24)$ & $1.75(1.25,7.30)$ \\
\hline Model $^{\text {a }}$ & 1 & $0.62(0.46,0.85)$ & $0.94(0.68,1.29)$ & $0.65(0.46,0.92)$ \\
\hline Model ${ }^{b}$ & 1 & $0.58(0.40,0.84)$ & $0.79(0.54,1.16)$ & $0.59(0.39,0.89)$ \\
\hline Secoisolariciresinol, median (range) & $0.03(0.00,0.05)$ & $0.06(0.05,0.08)$ & $0.11(0.08,0.14)$ & $0.21(0.14,0.90)$ \\
\hline Model $^{\text {a }}$ & 1 & $0.78(0.58,1.06)$ & $1.11(0.80,1.53)$ & $0.80(0.56,1.14)$ \\
\hline Model ${ }^{b}$ & 1 & $0.73(0.51,1.06)$ & $0.88(0.60,1.30)$ & $0.69(0.44,1.06)$ \\
\hline
\end{tabular}


In the multivariable-adjusted analysis individuals in the highest quartile of total phytoestrogen intake were less likely to be hypertensive (OR: 0.66, 95\% CI: 0.44-0.98); moreover, the association showed a significant decreasing trend (Table 2). Among the main classes of phytoestrogens, neither isoflavones nor lignans were associated with lower odds of hypertension. However, some individual compounds, such as biochanin A (OR: 0.63, 95\% CI: 0.41-0.96) and pinoresinol (OR: 0.59, 95\% CI: 0.39-0.89) showed an independent association with hypertension (Table 2). In the stratified analysis by sex (Supplementary Table S2), only dietary intake of pinoresinol in men was significantly inversely associated hypertension (OR: 0.47, 95\% CI: 0.23-0.93).

\section{Discussion}

The present study showed that individuals reporting higher intake of total phytoestrogens were less likely to be hypertensive. Interestingly, significant results were found only when considering total phytoestrogen intake, while no association was found for isoflavone and lignan intake individually. This finding suggests that phytoestrogens may share a common mechanism of action leading to the prevention of hypertension and that the necessary threshold to reach a clinically relevant effect was not reached when considering an individual group of molecules. However, consumption of both isoflavones and lignans was not significantly associated with hypertension and a larger sample with stronger statistical power may have had detected significant results also for both classes of phytoestrogens evaluated individually.

Results of this study are in line with some existing evidence related to phytoestrogens and cardiovascular health. Findings from randomized controlled trials provide the strongest evidence of causal effect but they are generally limited by the short duration and might be affected by the usual consumption of the examined compounds if diet is not controlled: for instance, trials conducted on Asian population with high habitual average phytoestrogen intake showed different results than trials conducted on Western population. However, meta-analyses of randomized controlled trials on soy supplementation showed a significant reduction in BP, despite results were not univocal: indeed, subgroup analyses showed more consistent evidence when considering hypertensive, but not normotensive individuals [15] with no dose-response relationship [16]. Meta-analyses of randomized controlled trials on lignan-rich foods, such as sesame [17], black cumin [18], and flaxseed [19], have provided evidence of a significant effect in reducing BP. Nevertheless, some randomized-controlled trials showed null or scanty significant results [20]. It is noteworthy to underline that most of the intervention trials provided supplementation of lignans at doses that might have been not sufficient to observe any relevant clinical effect. Observational studies may provide a more realistic picture of the habitual consumption of foods in a population, but they are affected by a several biases and potential confounding factors. The potential beneficial effect of several foods on hypertension has been pointed out [21-23]: summary evidence syntheses showed substantial beneficial effects of soy [24], nuts [25,26], legumes [27,28], coffee [29,30] on cardiovascular-related outcomes. However, previous observational studies specifically investigating phytoestrogens showed mixed results on their potential association with hypertension. A study conducted on European postmenopausal women showed that dietary isoflavones intake was not associated with several parameters of endothelial function [31]. However, the authors explored the aforementioned associations considering the exposure as continuous variables, which may affect the results due to the influence of extreme data estimates compared to categorization (i.e., quantiles). Another study conducted on Polish adults showed no association between isoflavones and lignans intake and features of metabolic syndrome, including impaired BP [32]; A prospective evaluation of the same cohort in relation to risk of hypertension substantially confirmed previous results [28].

As aforementioned in the introduction, it is noteworthy to consider that dietary sources of phytoestrogens in Mediterranean cohorts may differ from European, American, and Asian cohorts. Previous results from the MEAL cohort showed that the major food contributors to isoflavones intake were legumes (beans), nuts and seeds rather than soy foods, which were consumed in much lower 
amounts than the former, while major contributors of lignans were citrus fruits (including red orange), garlic, olive oil and bread [33]. These foods are characteristic of a traditional Mediterranean dietary pattern [34], which has been shown to be associated with potential benefits toward BP and inversely associated with hypertension in the MEAL cohort [35]. Interestingly, another study also showed that increasing isoflavones and lignans intake was associated with higher adherence to the Mediterranean diet, suggesting that these polyphenol groups may exert or mediate the potential beneficial effects of this dietary pattern on BP and endothelial function [36].

From a mechanistic point of view, several hypotheses have been proposed to explain the potential protective effects of dietary phytoestrogens on endothelial function. Primarily, phytoestrogens are able to emulate physiological responses equivalent to those evoked by physiological estrogens (i.e., endothelium-dependent vasodilatation) [23]. Isoflavones are thought to influence flow-mediated dilation through effects on the acute response cell-signaling pathways that increase nitric oxide (NO) production [37]. Moreover, isoflavones significantly reduce circulating adhesion molecules, such as intercellular adhesion molecule-1, (ICAM-1) vascular cell adhesion molecule-1 (VCAM-1), and E-selectin, which in turn reduce platelet activation, and may explain the antithrombotic and platelet aggregation inhibition effects of isoflavones [38]. Lignans have potent antioxidant properties and have been shown to decrease in vivo lipid peroxidation, which in turn may prevent endothelium damage and atheromatous plaque formation [39]. Another mechanism responsible for BP lowering effect of lignans is a NO-mediated vasorelaxation action [40]. Lignans have been demonstrated to directly decrease endothelin-1 synthesis and increase NO production, which in turn may lead to arterial vasodilation and to reduction in BP [40]. Moreover, the BP lowering properties of lignans may be independent of their anti-oxidative effect, acting through reduction of 20-hydroxyeicosatetraenoic (20-HETE) levels, a metabolite of arachidonic acid which has been hypothesized to play a key role in the pathogenesis of hypertension in humans [41].

To the best of our knowledge, this is the first study investigating the association between dietary phytoestrogens and hypertension in a Mediterranean cohort. However, the findings should be considered in light of some limitations. First, the cross-sectional design of the study may provide insights on the association between variables but causal relation cannot be concluded. Second, data on dietary phytoestrogens was derived from an FFQ (Food Frequency Questionnaire), which may be preferred to rank rather than to be used to derive the absolute amount of compounds. However, foods containing high amounts of phytoestrogens are most likely to be consumed periodically, rather than on a daily basis, thus an FFQ would be a preferable choice, compared to 24-h recalls, to estimate the dietary content of phytoestrogens. Moreover, used questionnaires provided a valid estimation of the foods that might contribute to the intake of isoflavones and lignans (i.e., fruits, vegetables, legumes, coffee, tea, nuts, and grain products). Another limitation of exploring dietary intake of phytoestrogens is the potential confounding effect of other compounds that have demonstrated BP-lowering effects, such as fiber and omega-3 polyunsaturated fatty acids, high SFA and Na intake [42,43]. Finally, several factors in addition to diet, such as intestinal microflora, smoking, antibiotics, and obesity may affect bioavailability and circulating phytoestrogen levels in the body; thus, additional studies on intermediary biomarkers of phytoestrogen consumption are warranted to confirm the results obtained in this study.

\section{Materials and Methods}

\subsection{Study Design and Population}

The MEAL study is an observational study designed in order to investigate the relationship between nutritional and lifestyle habits characterizing the classical Mediterranean area and non-communicable diseases. The baseline data included a random sample of 2044 men and women aged 18 or more years old, and randomly selected in the main districts of the city of Catania, southern Italy. The enrollment and data collection was performed between the years 2014 and 2015 through the 
selection among the lists of registered patients of a pool of general practitioners. Details of the study protocol are published elsewhere [44]. All participants were informed about the aims of the study and provided a written informed consent. All the study procedures were carried out in accordance with the Declaration of Helsinki (1989) of the World Medical Association. The study protocol has been reviewed and approved by the concerning ethical committee.

\subsection{Data Collection}

An electronic data collection was performed by face-to-face assisted personal interview using tablet computers. In order to visualize the response options, participants were provided with a paper copy of the questionnaire. However, final answers were registered directly by the interviewer. The demographic data included gender, age at recruitment, highest educational degree achieved, occupation (specifies the character of the most important employment during the year before the investigation) or last occupation before retirement, and marital status; educational status was categorized as (i) low (primary/secondary); (ii) medium (high school); and (iii) high (university). Occupational status was categorized as (i) unemployed; (ii) low (unskilled workers); (iii) medium (partially skilled workers); and (iv) high (skilled workers). Physical activity status was evaluated using International Physical Activity Questionnaires (IPAQ) [45], which included a set of questionnaires (5 domains) investigating the time spent being physically active in the last 7 days. Based on the IPAQ guidelines, final score allows categorizing physical activity level as (i) low; (ii) moderate; and (iii) high. Smoking status was categorized as (i) non-smoker; (ii) ex-smoker; and (iii) current smoker. Alcohol consumption was categorized as (i) none; (ii) moderate drinker (0.1-12 g/d) and (iii) regular drinker $(>12 \mathrm{~g} / \mathrm{d})$.

\subsection{Dietary Assessment}

The dietary assessment has been performed by the administration of two food frequency questionnaires (a long and a short version) that have been previously tested for validity and reliability for the Sicilian population [46,47]. The identification of the food intake, the energy content as well as the macro- and micro-nutrients intake were obtained through comparison with food composition tables of the Research Center for Foods and Nutrition [48]. Intake of seasonal foods referred to consumption during the period in which the food was available and then adjusted by its proportional intake in one year. FFQs with unreliable intakes $(<1000$ or $>6000 \mathrm{kcal} / \mathrm{d})$ were excluded from the analyses $(n=107)$ leaving a total of 1936 individuals included in the analysis.

\subsection{Estimation of Polyphenol Intake}

The process of the estimation of phytoestrogen intake has been previously described in detail [49]. Briefly, data on the polyphenol content in foods were retrieved from the Phenol-Explorer database (www.phenol-explorer.eu) [50,51]. A new version of the Phenol-Explorer database containing data on the effects of cooking and food processing on polyphenol contents was used whenever possible in order to apply polyphenol-specific retention factors [51]. Foods that contained no polyphenols were excluded from the calculation, leaving a total of 75 items included in the analyses. Food weight loss or gain during cooking was corrected using yield factors [52]. The average food consumption was calculated (in $\mathrm{g}$ or $\mathrm{mL}$ ) by following the standard portion sizes used in the study and then converted in 24-h intake. Finally, a search was carried out in the Phenol-Explorer database to retrieve mean content values for all polyphenols contained in the selected foods. Next, phytoestrogen intake from each food was calculated by multiplying the content of each phytoestrogen class by the daily consumption of each food. The total phytoestrogen intake was considered as the sum of total isoflavones and lignans; individual phytoestrogens, including the isoflavones daidzein, genistein and biochanin $\mathrm{A}$, and the lignans lariciresinol, matairesinol, pinoresinol, and seicoisolariciresinol were also calculated. Finally, pyhtoestrogens intake was adjusted for total energy intake (kcal/d) using the residual method [53]. 


\subsection{Anthropometric Measurements and Outcome Ascertainment}

Anthropometric measurements have been collected following standard procedures [54]. Arterial blood pressure (BP) was measured in sitting position and at least $5 \mathrm{~min}$ at rest at the end of the physical examination. Because of the possibility of differences in BP measurement, the measurements were taken three times at the right arm relaxed and well supported by a table, with an angle of $45^{\circ}$ from the trunk. A mean of the last two measurements was considered for inclusion in the database. Information from measurements was integrated with general practitioners computerized records, as patients are diagnosed with disease by a specialist in order to obtain drug reimbursement. Patients have been considered hypertensive when average systolic/diastolic BP levels were higher or equal to 140/90 mm Hg, taking anti-hypertensive medications, or being previously diagnosed of hypertension.

\subsection{Statistical Analysis}

Frequencies are expressed as absolute numbers and percentages; continuous variables are expressed as means and standard deviations. Individuals were divided into quartiles of dietary phytoestrogens intake and distribution of background characteristics were compared between groups. Differences were tested with Chi-square test for categorical variables, ANOVA for continuous variables distributed normally, and Kruskall-Wallis test for variables distributed not normally. A linear logistic regression analysis was performed to test the relation between total phytoestrogen intake and systolic and diastolic blood pressure (DBP). Age- and energy-adjusted multivariate logistic regression models were used to test association between variables of exposure (including total phytoestrogens and individual subclasses and specific compound intake) and having hypertension; additional multivariate models adjusted for all other background characteristics (age, sex, educational and occupational status, smoking and alcohol drinking habits, physical activity level, sodium and potassium intake) were also performed to test whether the observed associations were independent from the aforementioned potential confounding factors. All reported $p$-values were based on two-sided tests and compared to a significance level of 5\%. SPSS 17 (SPSS Inc., Chicago, IL, USA) software was used for all the statistical calculations.

\section{Conclusions}

In conclusions, dietary phytoestrogens are associated with lower likelihood of hypertension in adults living in the Mediterranean area. Future studies are needed to confirm the present findings (i.e., prospective cohort studies) and better understand the mechanisms underlying such associations.

Supplementary Materials: The following are available online at www.mdpi.com/xxx/s1, Supplementary Table S1: Background characteristics by quartiles of dietary phytoestrogens intake in the MEAL study sample separately for men and women, Supplementary Table S2: Association between quartiles of dietary phytoestrogens intake (total and main classes) and hypertension in men and women.

Acknowledgments: No funding.

Author Contributions: J.G. conceived and designed the study, performed analysis interpretation and manuscript drafting; J.G. and D.S. managed the data; D.S., I.B. and G.Z. performed the analysis; B.S., A.S., F.R.P. and M.M. provided insights on data interpretation and critically revised the paper. All authors critically revised and approved the final version of the manuscript.

Conflicts of Interest: The authors declare no conflict of interest.

\section{References}

1. Grosso, G.; Godos, J.; Lamuela-Raventos, R.; Ray, S.; Micek, A.; Pajak, A.; Sciacca, S.; D’Orazio, N.; Rio, D.D.; Galvano, F. A comprehensive meta-analysis on dietary flavonoid and lignan intake and cancer risk: Level of evidence and limitations. Mol. Nutr. Food Res. 2016. [CrossRef] [PubMed]

2. Grosso, G.; Micek, A.; Godos, J.; Pajak, A.; Sciacca, S.; Galvano, F.; Giovannucci, E.L. Dietary flavonoid and lignan intake and mortality in prospective cohort studies: Systematic review and dose-response meta-analysis. Am. J. Epidemiol. 2017, 185, 1304-1316. [CrossRef] [PubMed] 
3. Rietjens, I.; Louisse, J.; Beekmann, K. The potential health effects of dietary phytoestrogens. Br. J. Pharmacol. 2017, 174, 1263-1280. [CrossRef] [PubMed]

4. Rietjens, I.M.; Sotoca, A.M.; Vervoort, J.; Louisse, J. Mechanisms underlying the dualistic mode of action of major soy isoflavones in relation to cell proliferation and cancer risks. Mol. Nutr. Food Res. 2013, 57, $100-113$. [CrossRef] [PubMed]

5. Gencel, V.B.; Benjamin, M.M.; Bahou, S.N.; Khalil, R.A. Vascular effects of phytoestrogens and alternative menopausal hormone therapy in cardiovascular disease. Mini Rev. Med. Chem. 2012, 12, 149-174. [CrossRef] [PubMed]

6. Grosso, G.; Bella, F.; Godos, J.; Sciacca, S.; Del Rio, D.; Ray, S.; Galvano, F.; Giovannucci, E.L. Possible role of diet in cancer: Systematic review and multiple meta-analyses of dietary patterns, lifestyle factors, and cancer risk. Nutr. Rev. 2017, 75, 405-419. [CrossRef] [PubMed]

7. Kuhnle, G.G.; Dell'Aquila, C.; Aspinall, S.M.; Runswick, S.A.; Mulligan, A.A.; Bingham, S.A. Phytoestrogen content of beverages, nuts, seeds, and oils. J. Agric. Food Chem. 2008, 56, 7311-7315. [CrossRef] [PubMed]

8. Bai, W.; Wang, C.; Ren, C. Intakes of total and individual flavonoids by US adults. Int. J. Food Sci. Nutr. 2014, 65, 9-20. [CrossRef] [PubMed]

9. Zamora-Ros, R.; Knaze, V.; Lujan-Barroso, L.; Kuhnle, G.G.; Mulligan, A.A.; Touillaud, M.; Slimani, N.; Romieu, I.; Powell, N.; Tumino, R.; et al. Dietary intakes and food sources of phytoestrogens in the European prospective investigation into cancer and nutrition (epic) 24-hour dietary recall cohort. Eur. J. Clin. Nutr. 2012, 66, 932-941. [CrossRef] [PubMed]

10. Zappalà, G.; Buscemi, S.; Mulè, S.; La Verde, M.; D’Urso, M.; Corleo, D.; Marranzano, M. High adherence to Mediterranean diet, but not individual foods or nutrients, is associated with lower likelihood of being obese in a Mediterranean cohort. Eat. Weight Disord. 2017. [CrossRef] [PubMed]

11. Godos, J.; Sinatra, D.; Blanco, I.; Mule, S.; La Verde, M.; Marranzano, M. Association between dietary phenolic acids and hypertension in a mediterranean cohort. Nutrients 2017, 9, 1069. [CrossRef] [PubMed]

12. Tse, G.; Eslick, G.D. Soy and isoflavone consumption and risk of gastrointestinal cancer: A systematic review and meta-analysis. Eur. J. Nutr. 2016, 55, 63-73. [CrossRef] [PubMed]

13. Yu, Y.; Jing, X.; Li, H.; Zhao, X.; Wang, D. Soy isoflavone consumption and colorectal cancer risk: A systematic review and meta-analysis. Sci. Rep. UK 2016, 6, 25939. [CrossRef] [PubMed]

14. Xie, Q.; Chen, M.L.; Qin, Y.; Zhang, Q.Y.; Xu, H.X.; Zhou, Y.; Mi, M.T.; Zhu, J.D. Isoflavone consumption and risk of breast cancer: A dose-response meta-analysis of observational studies. Asia Pac. J. Clin. Nutr. 2013, 22, 118-127. [CrossRef] [PubMed]

15. Liu, X.X.; Li, S.H.; Chen, J.Z.; Sun, K.; Wang, X.J.; Wang, X.G.; Hui, R.T. Effect of soy isoflavones on blood pressure: A meta-analysis of randomized controlled trials. Nutr. Metab. Cardiovasc. Dis. 2012, 22, $463-470$. [CrossRef] [PubMed]

16. Taku, K.; Lin, N.; Cai, D.; Hu, J.; Zhao, X.; Zhang, Y.; Wang, P.; Melby, M.K.; Hooper, L.; Kurzer, M.S.; et al. Effects of soy isoflavone extract supplements on blood pressure in adult humans: Systematic review and meta-analysis of randomized placebo-controlled trials. J. Hypertens. 2010, 28, 1971-1982. [CrossRef] [PubMed]

17. Khosravi-Boroujeni, H.; Nikbakht, E.; Natanelov, E.; Khalesi, S. Can sesame consumption improve blood pressure? A systematic review and meta-analysis of controlled trials. J. Sci. Food Agric. 2017. [CrossRef] [PubMed]

18. Sahebkar, A.; Soranna, D.; Liu, X.; Thomopoulos, C.; Simental-Mendia, L.E.; Derosa, G.; Maffioli, P.; Parati, G. A systematic review and meta-analysis of randomized controlled trials investigating the effects of supplementation with nigella sativa (black seed) on blood pressure. J. Hypertens. 2016, 34, 2127-2135. [CrossRef] [PubMed]

19. Khalesi, S.; Irwin, C.; Schubert, M. Flaxseed consumption may reduce blood pressure: A systematic review and meta-analysis of controlled trials. J. Nutr. 2015, 145, 758-765. [CrossRef] [PubMed]

20. Peterson, J.; Dwyer, J.; Adlercreutz, H.; Scalbert, A.; Jacques, P.; McCullough, M.L. Dietary lignans: Physiology and potential for cardiovascular disease risk reduction. Nutr. Rev. 2010, 68, 571-603. [CrossRef] [PubMed]

21. Grosso, G.; Estruch, R. Nut consumption and age-related disease. Maturitas 2016, 84, 11-16. [CrossRef] [PubMed] 
22. Godos, J.; Pluchinotta, F.R.; Marventano, S.; Buscemi, S.; Li Volti, G.; Galvano, F.; Grosso, G. Coffee components and cardiovascular risk: Beneficial and detrimental effects. Int. J. Food Sci. Nutr. 2014, 65, 925-936. [CrossRef] [PubMed]

23. Ramdath, D.D.; Padhi, E.M.; Sarfaraz, S.; Renwick, S.; Duncan, A.M. Beyond the cholesterol-lowering effect of soy protein: A review of the effects of dietary soy and its constituents on risk factors for cardiovascular disease. Nutrients 2017, 9, 324. [CrossRef] [PubMed]

24. Yan, Z.; Zhang, X.; Li, C.; Jiao, S.; Dong, W. Association between consumption of soy and risk of cardiovascular disease: A meta-analysis of observational studies. Eur. J. Prev. Cardiol. 2017, 24, 735-747. [CrossRef] [PubMed]

25. Guo, K.; Zhou, Z.; Jiang, Y.; Li, W.; Li, Y. Meta-analysis of prospective studies on the effects of nut consumption on hypertension and type 2 diabetes mellitus. J. Diabetes 2015, 7, 202-212. [CrossRef] [PubMed]

26. Grosso, G.; Yang, J.; Marventano, S.; Micek, A.; Galvano, F.; Kales, S.N. Nut consumption on all-cause, cardiovascular, and cancer mortality risk: A systematic review and meta-analysis of epidemiologic studies. Am. J. Clin. Nutr. 2015, 101, 783-793. [CrossRef] [PubMed]

27. Afshin, A.; Micha, R.; Khatibzadeh, S.; Mozaffarian, D. Consumption of nuts and legumes and risk of incident ischemic heart disease, stroke, and diabetes: A systematic review and meta-analysis. Am. J. Clin. Nutr. 2014, 100, 278-288. [CrossRef] [PubMed]

28. Marventano, S.; Izquierdo Pulido, M.; Sanchez-Gonzalez, C.; Godos, J.; Speciani, A.; Galvano, F.; Grosso, G. Legume consumption and cvd risk: A systematic review and meta-analysis. Public Health Nutr. 2017, 20, 245-254. [CrossRef] [PubMed]

29. Grosso, G.; Micek, A.; Godos, J.; Sciacca, S.; Pajak, A.; Martinez-Gonzalez, M.A.; Giovannucci, E.L.; Galvano, F. Coffee consumption and risk of all-cause, cardiovascular, and cancer mortality in smokers and non-smokers: A dose-response meta-analysis. Eur. J. Epidemiol. 2016, 31, 1191-1205. [CrossRef] [PubMed]

30. Steffen, M.; Kuhle, C.; Hensrud, D.; Erwin, P.J.; Murad, M.H. The effect of coffee consumption on blood pressure and the development of hypertension: A systematic review and meta-analysis. J. Hypertens. 2012, 30, 2245-2254. [CrossRef] [PubMed]

31. Kreijkamp-Kaspers, S.; Kok, L.; Bots, M.L.; Grobbee, D.E.; van der Schouw, Y.T. Dietary phytoestrogens and vascular function in postmenopausal women: A cross-sectional study. J. Hypertens. 2004, 22, 1381-1388. [CrossRef] [PubMed]

32. Grosso, G.; Stepaniak, U.; Micek, A.; Stefler, D.; Bobak, M.; Pajak, A. Dietary polyphenols are inversely associated with metabolic syndrome in polish adults of the hapiee study. Eur. J. Nutr. 2016. [CrossRef] [PubMed]

33. Godos, J.; Marventano, S.; Mistretta, A.; Galvano, F.; Grosso, G. Dietary sources of polyphenols in the mediterranean healthy eating, aging and lifestyle (meal) study cohort. Int. J. Food Sci. Nutr. 2017, 68, 750-756. [CrossRef] [PubMed]

34. Marventano, S.; Godos, J.; Platania, A.; Galvano, F.; Mistretta, A.; Grosso, G. Mediterranean diet adherence in the mediterranean healthy eating, aging and lifestyle (meal) study cohort. Int. J. Food Sci. Nutr. 2017, 69, 100-107. [CrossRef] [PubMed]

35. La Verde, M.; Mule, S.; Zappala, G.; Privitera, G.; Maugeri, G.; Pecora, F.; Marranzano, M. Higher adherence to the mediterranean diet is inversely associated with having hypertension: Is low salt intake a mediating factor? Int. J. Food Sci. Nutr. 2017, 1-10. [CrossRef] [PubMed]

36. Godos, J.; Rapisarda, G.; Marventano, S.; Galvano, F.; Mistretta, A.; Grosso, G. Association between polyphenol intake and adherence to the mediterranean diet in sicily, southern italy. NFS J. 2017, 8, 1-7. [CrossRef]

37. Hall, W.L.; Rimbach, G.; Williams, C.M. Isoflavones and endothelial function. Nutr. Res. Rev. 2005, 18, 130-144. [CrossRef] [PubMed]

38. Santhakumar, A.B.; Bulmer, A.C.; Singh, I. A review of the mechanisms and effectiveness of dietary polyphenols in reducing oxidative stress and thrombotic risk. J. Hum. Nutr. Diet. 2014, 27, 1-21. [CrossRef] [PubMed]

39. Prasad, K. Flaxseed and cardiovascular health. J. Cardiovasc. Pharmacol. 2009, 54, 369-377. [CrossRef] [PubMed]

40. Adlercreutz, H. Lignans and human health. Crit. Rev. Clin. Lab. Sci. 2007, 44, 483-525. [CrossRef] [PubMed] 
41. Hallmans, G.; Zhang, J.X.; Lundin, E.; Stattin, P.; Johansson, A.; Johansson, I.; Hulten, K.; Winkvist, A.; Aman, P.; Lenner, P.; et al. Rye, lignans and human health. Proc. Nutr. Soc. 2003, 62, 193-199. [CrossRef] [PubMed]

42. Fuller, S.; Beck, E.; Salman, H.; Tapsell, L. New horizons for the study of dietary fiber and health: A review. Plant Foods Hum. Nutr. 2016, 71, 1-12. [CrossRef] [PubMed]

43. Marventano, S.; Kolacz, P.; Castellano, S.; Galvano, F.; Buscemi, S.; Mistretta, A.; Grosso, G. A review of recent evidence in human studies of n-3 and n-6 pufa intake on cardiovascular disease, cancer, and depressive disorders: Does the ratio really matter? Int. J. Food Sci. Nutr. 2015, 66, 611-622. [CrossRef] [PubMed]

44. Grosso, G.; Marventano, S.; D'Urso, M.; Mistretta, A.; Galvano, F. The mediterranean healthy eating, ageing, and lifestyle (meal) study: Rationale and study design. Int. J. Food Sci. Nutr. 2017, 68, 577-586. [CrossRef] [PubMed]

45. Craig, C.L.; Marshall, A.L.; Sjostrom, M.; Bauman, A.E.; Booth, M.L.; Ainsworth, B.E.; Pratt, M.; Ekelund, U.; Yngve, A.; Sallis, J.F.; et al. International physical activity questionnaire: 12-country reliability and validity. Med. Sci. Sport Exerc. 2003, 35, 1381-1395. [CrossRef] [PubMed]

46. Buscemi, S.; Rosafio, G.; Vasto, S.; Massenti, F.M.; Grosso, G.; Galvano, F.; Rini, N.; Barile, A.M.; Maniaci, V.; Cosentino, L.; et al. Validation of a food frequency questionnaire for use in italian adults living in sicily. Int. J. Food Sci. Nutr. 2015, 66, 426-438. [CrossRef] [PubMed]

47. Marventano, S.; Mistretta, A.; Platania, A.; Galvano, F.; Grosso, G. Reliability and relative validity of a food frequency questionnaire for Italian adults living in Sicily, southern Italy. Int. J. Food Sci. Nutr. 2016, 67, 857-864. [CrossRef] [PubMed]

48. Istituto Nazionale di Ricerca per gli Alimenti e la Nutrizione. Tabelle di Composizione Degli Alimenti; INRAN: Rome, Italy, 2009.

49. Platania, A.; Zappala, G.; Mirabella, M.U.; Gullo, C.; Mellini, G.; Beneventano, G.; Maugeri, G.; Marranzano, M. Association between Mediterranean diet adherence and dyslipidaemia in a cohort of adults living in the Mediterranean area. Int. J. Food Sci. Nutr. 2017. [CrossRef] [PubMed]

50. Neveu, V.; Perez-Jiménez, J.; Vos, F.; Crespy, V.; Du Chaffaut, L.; Mennen, L.; Knox, C.; Eisner, R.; Cruz, J.; Wishart, D.; et al. Phenol-Explorer: An Online Comprehensive Database on Polyphenol Contents in Foods. Database 2010. [CrossRef] [PubMed]

51. Rothwell, J.A.; Perez-Jimenez, J.; Neveu, V.; Medina-Remon, A.; M'Hiri, N.; Garcia-Lobato, P.; Manach, C.; Knox, C.; Eisner, R.; Wishart, D.S.; et al. Phenol-explorer 3.0: A major update of the phenol-explorer database to incorporate data on the effects of food processing on polyphenol content. Database J. Biol. Databases Curation 2013, 2013, bat070. [CrossRef] [PubMed]

52. Bognar, A. Tables on Weight Yield of Food and Retention Factors of Food Constituents for the Calculation of Nutrient Composition of Cooked Foods (Dishes); BFE: Karlsruhe, Germany, 2002.

53. Willett, W.; Lenart, E. Reproducibility and validity of food frequency questionnaire. In Nutritional Epidemiology, 2nd ed.; Oxford University Press: New York, NY, USA, 1998.

54. Mistretta, A.; Marventano, S.; Platania, A.; Godos, J.; Galvano, F.; Grosso, G. Metabolic profile of the mediterranean healthy eating, lifestyle and aging (meal) study cohort. Mediterr. J. Nutr. Metab. 2017, 10, 131-140. [CrossRef]

Sample Availability: Samples of the compounds are not available from the authors. 